ing and management of domestic animals ; in introducing the subject, the author is less concerned with the animals than with their position in domestic trade and the economics of their production. Thus, of ten chapters dealing with beef cattle, one is devoted to feeding and management and one to breeding : the remainder concern show-points and classes, marketing, meat grading, by-products and consumption, together with a brief historical introduction. Extensive use is made of statistics from packing-houses, U.S. Department of Agriculture surveys and the like, dealing with such matters as seasonal fluctuations in market receipts and prices, percentage losses through injury in shipment by rail or road, average live-weights at slaughter-houses, milk distribution costs, and so on. A list of slaughter-house by-products and their disposition extends to incense and oriental medicine. In contrast, no details are given of the composition of feeding stuffs, nor is there any mention of the ruminant stomach (except as tripe). Similarly, though wastage in dairy cattle is very high, there is no discussion of the causes. A curious omission is the absence of any reference to machine milking.

Housing, feeding and breeding are dealt with very briefly ; a survey is given of usual practices and of economic aspects such as the price equivalents of corn and butterfat. Certain remarks on management have a very practical ring and a more than local application. Two may be quoted here : "To top the market with beef steers is the fond hope of many cattle producers. . . . It is not always related to the most profit from the feeding enterprise" ; and again, of sheep : "Not all pure-bred flocks exhibit sheep at shows and expositions, but fitting for sale is essential for selling to the best advantage. Likewise a purebred flock manager should have salesmanship ability. The showing of a flock at the livestock shows is a form of advertising ..."

Prof. Anderson has aimed at the presentation of facts and the avoidance of matters of controversy. $\mathrm{He}$ has made much use of the findings of technical investigations. Some three hundred illustrations portray for the most part ideal breed types, industrial processes and price and population trends.

\section{FUNDAMENTALS OF ASTRONOMY}

\section{From Atoms to Stars}

By Dr. Martin Davidson. Pp. 188. (London, New York and Melbourne: Hutchinson's Scientific and Technical Publications, 1944.) 15s. net.

$\mathrm{B}$ OOKS written with the view of meeting the enlarged interest in astronomy manifested by the ordinary individual in recent years have not been lacking on either side of the Atlantic. One of the latest, for British readers, bears the comprehensive, if somewhat inconsequent, title "From Atoms to Stars" and is from the pen of Dr. Martin Davidson, prominent among British astronomers for his wide theoretical knowledge of the subject. To quote from the preface, it is "intended to provide a general outline of the most up-to-date knowledge of the heavenly bodies and also to show the methods employed by the astronomer to derive their distances, sizes, masses, temperatures, etc. . . ."

It is the latter aim which gives to the book its distinctive character. As if to warrant the title,
Chapter I is devoted to an account of the structure of the atom, according to present views, touching upon ionization, radioactivity, transmutation and allied phenomena. The reader is thus prepared for a description, later in the book, of the sub-atomic processes by which the enormous output of radiant energy continuously emitted by the sun and the stars has been maintained for thousands of millions of years.

The succeeding chapters follow the general plan adopted in books of this type. They deal in turn with the sun, the earth and the moon and phenomena relating to these bodies; next with the other members of the planetary system, including meteors and comets; and then five chapters are devoted to the stellar universe at large, in all its diversity of objects. Positional astronomy and star-configuration find no place in the book.

Each chapter contains, in addition to ample descriptive and explanatory matter, much interesting detail of a kind not commonly found in nontechnical books; while in a few cases a short biblio. graphy is appended for the information of readers who may wish to enter more deeply into the subject.

Dr. Davidson's mathematical bent finds an outlet in the fulfilment of his promise to show how astronomers tackle their theoretical problems. Many worked examples are incorporated in the text, most of them being in reality quite elementary, and some, perhaps, given at unnecessary length. This plan makes it difficult for readers to avoid the arithmetic even though they may wish merely to know the methods.

The final chapter contains a summary of various theories of the origin of the sun's planetary system, beginning with those of Kant and Laplace and concluding with several speculations of very recent date. The author is of opinion that none is really satisfactory.

A few typographical mistakes have slipped through the 'proof' stage-chiefly transposition of digits, of which the outstanding example is on page 132, where the value of a radian in degrees is stated to be $\pi / 180$ instead of $180 / \pi$. On pages 152, 153 " $F$. C. Adams" is a slip for Walter S. Adams. The director of Mount Wilson Observatory, California, is of course not to be confused with the ever-famous Prof. J. C. Adams of Cambridge, who first demonstrated the existence of the planet Neptune, which was discovered later. It is surprising, also, to find Dr. Davidson giving renewed currency to the idea that the double high tides experienced at certain places-for example, at Southampton-are due to the successional arrival of the tidal wave by two different routes. This superficially plausible explanation has been shown by such authorities as Lord Kelvin and Sir George Darwin to be fallacious.

The book is illustrated with excellent photographs and many instructive diagrams. The style is pleasantly colloquial, though a feeling sometimes arises that the author, in compressing his material, is unconsciously stepping above the standard envisaged in his preface, and is taking for granted rather more astronomical knowledge than the average reader would be likely to possess. Nevertheless, to readers with ordinary scientific outlook, "From Atoms to Stars" can be heartily recommended as an authoritative, up-to-date outline of astronomy's wonderful achievements in the exploration of the infinities both of space and time.
W. M. WITCEeLL. 